\title{
WAITING TIME OF PHARMACY SERVICE AS AN INDICATOR OF PATIENT SATISFACTION: A SYSTEMATIC REVIEW
}

\author{
Dyani Kusumowardhani, Yaslis Ilyas \\ Masters Program in Public Health, Faculty of Public Health, Universitas Indonesia
}

\begin{abstract}
Background: The success of health service is reflected in patient satisfaction. Attributes of quality health service included the speed of pharmaceutical service. The Community Satisfaction Index Survey conducted by the Ministry of Health in 2017 in several government hospitals reported patients complained about the duration of drug preparation. This study aimed to systematically review the waiting time of pharmacy service as an indicator of patient satisfaction.

Subjects and Method: A systematic review was conducted by collecting articles obtained through PubMed and Scopus databases. The keywords were "pharmacy service", "waiting time", and "satisfaction". Articles were limited to those in English and published from 2010 to 2019. The data were selected by PRISMA flow diagram method.

Results: Five studies reported that waiting time for pharmaceutical service, including drug preparation, affected patient satisfaction. Intervention in the pharmaceutical service system both in hospitals and in general dispensaries might improve waiting times for drug preparation. Interventions vary from dispensing systems to drive-thru drug taking, without adding additional human resources (HR).

Conclusion: Patient satisfaction increases with the short waiting time in drug preparation. Alternative intervention needs to be done as an effort to shorten the waiting time for drug preparation if the addition of HR is not possible.
\end{abstract}

Keywords: pharmaceutical service, waiting time, satisfaction

\section{Correspondence:}

Dyani Kusumowardhani. Masters Program in Public Health, Faculty of Public Health, Universitas Indonesia, Depok, West Java, Indonesia. Email: dyanikusumo@yahoo.com. Mobile: +6281399173781.

The $6^{\text {th }}$ International Conference on Public Health Best Western Premier Hotel, Solo, Indonesia, October 23-24, 2019 | 290

https://doi.org/10.26911/the6thicph.04.52 